\title{
Linking Identity and Depressive Symptoms Across Adolescence: A Multisample Longitudinal Study Testing Within-Person Effects
}

\author{
Andrik I. Becht \\ Utrecht University and Leiden University \\ Stefanie A. Nelemans \\ Utrecht University
}

\author{
Koen Luyckx \\ Catholic University of Leuven \\ Luc Goossens \\ Catholic University of Leuven
}

\author{
Susan J. T. Branje, Wilma A. M. Vollebergh, and Wim H. J. Meeus \\ Utrecht University
}

\begin{abstract}
This multisample longitudinal study examined the directionality of effects between identity exploration and commitment processes and depressive symptoms across adolescence. We compared two theoretical perspectives. According to the vulnerability model, identity uncertainty predicts depressive symptoms, whereas the scar model holds that depressive symptoms play into identity uncertainty. In investigating both models, we examined reciprocal within-person associations in Study $1\left(N=497, M_{\text {age }}\right.$ Time 1 $[\mathrm{T} 1]=14.03$ years, comprising five annual waves $)$ and Study $2\left(N=1,022, M_{\text {age }} \mathrm{T} 1=15.80\right.$ years, comprising four annual waves). To this end, we applied the random-intercept cross-lagged panel model (RI-CLPM) in both studies. Results supported the vulnerability model across Studies 1 and 2. Specifically, within-person increasing reconsideration of commitment (Study 1) and ruminative exploration (Study 2) predicted a within-person increase in depressive symptoms 1 year later, but not vice versa. Commitment processes did not predict depressive symptoms at the within-person level. Our findings indicate that maladaptive exploration processes of identity formation play a particularly important role in the development of depressive symptoms at the within-person level.
\end{abstract}

Keywords: identity formation, adolescence, depressive symptoms, certainty-uncertainty dynamics, random intercept cross-lagged panel model

Supplemental materials: http://dx.doi.org/10.1037/dev0000742.supp

Many youth experience a rise in depressive symptoms during adolescence (for a review of longitudinal studies, see Meeus, 2016). For some adolescents, this temporal peak in depressive symptoms will again decline after a while. Others, however, continue to be at risk for elevated rates of depressive symptoms beyond adolescence (Petersen et al., 1993). Critically, even the development of subclinical levels of depression in adolescence is considered to be a stepping stone for a clinical diagnosis of depression in adulthood (Hankin et al., 2015; Petersen et al., 1993). Therefore, it is crucial to advance our understanding of possible risk factors for the development of depressive symptoms in adolescence (Kessler et al., 2005).

As a vital developmental task for adolescents is to develop their own identity (Erikson, 1968), ongoing uncertainty in this process of identity formation may be a risk factor for the development of depressive symptoms over time. During this process of identity
This article was published Online First May 9, 2019.

Andrik I. Becht, Research Center Adolescent Development, Utrecht University and Brain and Development Lab, Developmental and Educational Psychology Unit, Leiden University; Koen Luyckx, Department of Psychology, Catholic University of Leuven; Stefanie A. Nelemans, Research Center Adolescent Development, Utrecht University; Luc Goossens, Department of Psychology, Catholic University of Leuven; Susan J. T. Branje, Research Center Adolescent Development, Utrecht University; Wilma A. M. Vollebergh, Department of Interdisciplinary Social Sciences, Utrecht University; Wim H. J. Meeus, Research Center Adolescent Development, Utrecht University.

Funding for this research was obtained by a Van der Gaag Grant of the Royal Netherlands Academy of Arts and Sciences, awarded to Andrik I.
Becht. Data of the Research on Adolescent Development and Relationships (RADAR) study were used. RADAR has been financially supported by main grants from the Netherlands Organisation for Scientific Research (Grant GB-MAGW 480-03-005), and Stichting Achmea Slachtoffer en Samenleving to RADAR principal investigators, and from the Netherlands Organisation for Scientific Research to the Consortium Individual Development (Grant 024.001.003). Data of the Personality and Loneliness/Solitude (PALS) study were used. PALS has been financially supported by a grant from the Fund for Scientific Research Flanders (Grant G.0502.09).

Correspondence concerning this article should be addressed to Andrik I. Becht, Research Center Adolescent Development, Utrecht University, P.O Box 80 140, 3508 TC Utrecht, the Netherlands. E-mail: a.i.becht@uu.nl 
formation, critical questions are "Who am I" and "What direction do I want to take in life?" Contemporary models emphasize that identity formation is best described by both adaptive and maladaptive processes of identity exploration and commitment (Crocetti, Rubini, \& Meeus, 2008; Luyckx, Schwartz, Goossens, Soenens, \& Beyers, 2008). As identity formation can be quite stressful, those adolescents who are unable to develop firm commitments and continue to be highly uncertain about who they are, might especially be at risk for developing depressive symptoms (Erikson, 1968; Klimstra \& Denissen, 2017). A number of studies have indeed indicated that adolescents' identity uncertainty and depressive symptoms are positively correlated (Luyckx, Klimstra, Duriez, Van Petegem, \& Beyers, 2013; Luyckx, Schwartz, Goossens, et al., 2008; Schwartz et al., 2011). Despite this consensus on the linkage between identity and depressive symptoms, the directional nature of this association remains unclear (Klimstra \& Denissen, 2017). Further, these previous associations have been limited to the between-person level, hence indicating whether individuals scoring high on identity uncertainty relative to the rest of the sample, also score high on depressive symptoms, again relative to the rest of the sample (Curran \& Bauer, 2011). Therefore, this study aimed to test theoretical claims regarding the directionality of within-person effects linking identity processes to depressive symptoms in two large longitudinal adolescent samples.

\section{Identity Processes}

To be able to assess such prospective within-person associations between identity and depressive symptoms, it is crucial to assess identity from a fine-grained, process-oriented perspective. Recently, two conceptually related identity models, both building upon and extending Marcia's (1980) seminal identity status paradigm, identified different processes in how adolescents' deal with identity issues (Crocetti, 2017; Crocetti et al., 2008; Luyckx, Schwartz, Berzonsky, et al., 2008).

First, the Meeus-Crocetti model (Crocetti et al., 2008) posits three identity processes that are involved in identity development. Commitment refers to strong choices adolescents have made and the certainty they derive from these choices. In-depth exploration captures adolescents' continuous monitoring of their present commitments to further strengthen and maintain them. Reconsideration of commitment represents adolescents' uncertainty and willingness to abandon current commitments and search for new ones. Together, these processes capture the certainty-uncertainty dynamic of identity formation, which closely resembles Erikson's (1968) dynamic of identity synthesis versus identity confusion. On the one hand, identity synthesis, or identity certainty, is determined by the strength of adolescents ' commitments and in-depth exploration of these commitments. On the other hand, identity confusion, or identity uncertainty, is captured by adolescents' questioning their commitments and reconsidering alternative ones (Meeus, van de Schoot, Keijsers, Schwartz, \& Branje, 2010).

Second, the model developed by Luyckx and colleagues (Luyckx, Schwartz, Berzonsky, et al., 2008) also assesses adolescents' certainty about their commitments with similar processes as in the Meeus-Crocetti model. Specifically, identity certainty is assessed with the process of identification with commitments, tapping into the degree to which adolescents feel certain about and identify with their commitments, and the process of in-depth exploration, or the in-depth evaluation of one's existing commitments to further strengthen them. The identity uncertainty component in the Luyckx, Schwartz, Berzonsky, et al.'s (2008) model is captured by the process of ruminative exploration, indicative of adolescents getting stuck in the exploration process and experiencing distress. Although the Luyckx model includes two other identity processes (i.e., in-breadth exploration and commitment making), identification with commitment, exploration in-depth, and ruminative exploration processes are most closely related to the three identity processes in the Meeus-Crocetti model (Crocetti, 2017; Crocetti et al., 2008). Therefore, the present study used these three identity processes to examine the directional nature between identity and depressive symptoms across adolescence.

While previous identity formation models considered exploration primarily as an adaptive process (e.g., Marcia, 1966), exploration has been inconsistently related to both adjustment and maladjustment (Crocetti, 2017). Therefore, the more fine-grained Meeus-Crocetti model and the Luyckx model distinguish between specific adaptive and maladaptive identity processes. Specifically, commitment, identification with commitment, and in-depth exploration primarily tap into the adaptive processes of identity formation, whereas reconsideration of commitment and ruminative exploration capture the maladaptive and stressful processes of identity formation. The identity processes in the Meeus-Crocetti model and the Luyckx model each have their specific focus, however. For instance, reconsideration of commitment (as assessed in the MeeusCrocetti model), taps into adolescents' search for alternative commitments, when the present ones are not satisfying anymore, whereas ruminative exploration (as assessed in the Luyckx model) captures adolescents' more generic questioning (and accompanying hesitation) of the direction they want to take in their life. At a more general level, however, both identity processes capture the maladaptive and stressful aspects of identity formation. Further supporting this maladaptive nature of both reconsideration of commitment and ruminative exploration, higher levels on these respective identity processes have been consistently associated with more adjustment problems (internalizing and externalizing problem behaviors), poor family relationships, and low academic achievement (Crocetti, 2017; Luyckx, Schwartz, Berzonsky, et al., 2008; Meeus, 2011).

\section{Linkages Between Identity Processes and Depressive Symptoms}

Borrowing from the field of personality psychology, two dominant but contrasting perspectives can be distinguished regarding the direction of associations linking identity and depressive symptoms. According to the vulnerability/predisposition model, ineffectively dealing with identity issues may predispose adolescents to develop depressive symptoms over time (Durbin \& Hicks, 2014). The vulnerability model has received empirical support in a limited number of longitudinal studies. Specifically, adolescents in an identity status characterized by lower commitment levels and higher levels of identity reconsideration or ruminative exploration (i.e., adolescents in a moratorium identity status) reported higher levels of depressive symptoms compared with adolescents with stronger identity commitments and lower levels of reconsideration and ruminative exploration (i.e., adolescents in identity achievement and foreclosure type of statuses; Luyckx, Duriez, Klimstra, \& De Witte, 2010; Meeus, van de Schoot, Keijsers, \& Branje, 2012). Similarly, fluctuations in reconsideration 
of identity commitments predicted later depressive symptoms in adolescence (Schwartz et al., 2011). These findings tentatively suggest that especially maladaptive identity exploration processes indicative of identity uncertainty (i.e., ruminative exploration and reconsideration of commitment) would predict individuals to develop depressive symptoms over time.

In contrast, the scar model holds that experiencing depressive symptoms may affect adolescents' capacity to form strong identity commitments (Durbin \& Hicks, 2014; Klimstra \& Denissen, 2017). Adolescents who experience depressive symptoms often feel less agency and motivation to pursue valued goals as well. Because goal directedness and motivation to pursue valued goals are important capacities to form strong commitments (Becht et al., 2018; Burrow \& Hill, 2011), more depressed adolescents may be less able to develop strong commitments over time as well, as predicted by the scar model. Consistent with this hypothesis, depressive symptoms have been found to predict weaker identity commitments over time in adolescence (Schwartz, Klimstra, Luyckx, Hale, \& Meeus, 2012). In sum, both theoretical perspectives have received preliminary support in a limited number of longitudinal studies.

\section{Need for a Longitudinal Within-Person Approach}

Unfortunately, however, most studies on the linkages between identity and depressive symptoms are still cross-sectional, which makes it impossible to substantiate claims regarding the direction of associations (Klimstra \& Denissen, 2017). And, if longitudinal studies were employed, their design often did not provide insight in the direction of associations, for example, because these studies did not control for the stability of identity and depressive symptoms over time (Klimstra \& Denissen, 2017). Second, previous studies did not distinguish stable between-person effects from within-person effects. Therefore, these studies have mainly examined whether adolescents who have higher levels of identity uncertainty than other adolescents develop relatively more depressive symptoms than other adolescents. Yet, most developmental theories aim to describe and predict within-person processes, that is, how a change in an adolescent's identity uncertainty is related to that same adolescent's change in depressive symptoms over time, and vice versa. Because effects at the between-person level are often unrelated to the within-person effects (Hamaker, Kuiper, \& Grasman, 2015), and often uninformative when applied to associations between variables at the within-person level (Molenaar \& Campbell, 2009), it is vital to examine the direction of associations between identity and depressive symptoms at the within-person level.

\section{The Present Study}

In sum, the present study employed two conceptually similar identity process-oriented models to test the within-person directionality of associations between identity and depressive symptoms, allowing us to examine the robustness of associations across these identity models. Given the inconclusive empirical evidence on the longitudinal linkages between identity and depressive symptoms, we posited the vulnerability model and scar model against each other. Based on the vulnerability model, one would expect that adolescents with increasing identity uncertainty (indicated by lower commitments and higher levels of identity recon- sideration or ruminative exploration in Study 1 and Study 2, respectively) would be most likely to develop depressive symptoms over time. If the scar model holds, however, we would expect that experiencing depressive symptoms would undermine adolescents' capacity to develop a strong identity, and experience increasing identity uncertainty over time (indicated by lower commitment levels, and higher levels of identity reconsideration and ruminative exploration processes). Given the mixed evidence of the role of in-depth exploration in predicting internalizing behaviors (Crocetti, 2017), we explored the longitudinal directionality of associations between in-depth exploration and depressive symptoms in Study 1 and Study 2. Noteworthy, both the vulnerability and scar models are not mutually exclusive. As such, identity and depressive symptoms may also mutually influence each other over time. Given known gender differences in identity processes (Klimstra, Hale, Raaijmakers, Branje, \& Meeus, 2010) and the development of depressive symptoms (for a review of longitudinal studies, see Meeus, 2016), we also examined to what extent longitudinal associations between identity processes and depressive symptoms might be different for boys and girls. We tested these hypotheses in two longitudinal community samples of adolescents from the Netherlands and Flanders, the Dutch-speaking part of Belgium (Studies 1 and 2, including five and four annual measurement waves, respectively).

\section{General Methodological and Statistical Approach}

To test the direction of associations between identity and depressive symptoms at the within-person level in Studies 1 and 2, we applied a random-intercept cross-lagged panel model (RICLPM; Hamaker et al., 2015). This modeling approach is different from regular cross-lagged panel modeling because it separates the variance of each studied construct (i.e., the identity processes and depressive symptoms in our study) into (a) a stable betweenperson traitlike component, and (b) a within-person fluctuating component. The first between-person component is captured with random intercepts. The second within-person fluctuation component represents adolescents' fluctuations from measurement wave to measurement wave around their expected score. This expected score is based on the sample mean across waves and the individual's stable between-person component (i.e., the random intercept). As a result, the variance at the within-person level captures adolescents' fluctuations from wave to wave relative to their own expected score, rather than a rank order of scores of different individuals. Hence, by separating stable between-person differences in identity and depressive symptoms from the within-person fluctuations around these stable between-person differences, it is possible to test how identity and depressive symptoms are associated within the same person across time. Thus, the cross-lagged parameter can now be interpreted as the extent to which a change in an adolescent's identity (or depressive symptoms) score compared with his or her expected score is related to that same adolescent's deviation from the adolescents' expected depressive symptoms score (or identity) on the next wave (Hamaker et al., 2015; Keijsers, 2016).

We constructed two RI-CLPMs for Study 1 and Study 2, respectively. In each model we examined (a) within-person crosslagged paths from identity commitment, reconsideration of commitment, and in-depth exploration to depressive symptoms one 
year later (Study 1), and from identification of commitment, ruminative exploration, and in-depth exploration to depressive symptoms 1 year later (Study 2), as well as all possible reverse paths (e.g., from depressive symptoms to the respective identity processes). In addition, we controlled for (b) 1-year within-person stability paths (e.g., depressive symptoms at Time 1 (T1) predicting depressive symptoms at Time 2 (T2), and (c) within-time correlations between all study variables. Next to the cross-lagged effects between all identity processes and depressive symptoms, we also included all possible reciprocal associations among the identity processes in the models. To evaluate model fit, we used the comparative fit index (CFI), the root-mean-square error of approximation (RMSEA), and the standardized root-mean-square residual (SRMR). CFI values $\geq .90$, RMSEA $\leq .08$ and $\mathrm{SRMR} \leq$ .08 indicate acceptable model fit (Byrne, 2013). In both Study 1 and Study 2, visual inspection of Q-Q plots and histograms revealed that especially the distribution of scores on reconsideration, identification with commitment, and depressive symptoms were not normally distributed (reconsideration and depressive symptoms scores were positively skewed, and identification with commitment scores were negatively skewed). Therefore, we estimated our models with the robust MLR estimator to account for these nonnormal distributions (Muthén, 2010).

In order to create the most parsimonious model, we investigated whether the longitudinal associations between identity and depressive symptoms were time-invariant across adolescence. To this end, we tested whether cross-lagged effects, stability paths, and within-time correlations (Times 2-5 [T2-T5] in Study 1 and Times 2-4 [T2-T4] in Study 2) could be constrained across time. Therefore, we compared the unconstrained model with the model in which the cross-lagged effects, stability paths, and within-time correlations were set equal across time. We applied the Satorra Bentler $\chi 2(\mathrm{~S}-\mathrm{B} \chi 2)$ difference test to evaluate whether these parameters could be constrained over time.

\section{Study 1}

\section{Method}

Participants and procedure. Participants were 497 Dutch adolescents ( 283 boys $M_{\text {age }} \mathrm{T} 1=14.03$ years, $S D=0.46$, range 12-17 years) from the ongoing longitudinal project Research on Adolescent Development and Relationships-Young Cohort (RADAR-Y; Branje \& Meeus, 2018). All participants were born in the Netherlands and were fluent in Dutch. Most adolescents $(89 \%)$ came from medium to high socioeconomic backgrounds. The majority of adolescents lived with both parents (86\%); some lived with their mother $(9 \%)$ or in another family constellation $(5 \%)$. On average, mothers were aged 45.40 years $(S D=4.45)$, and fathers were aged 47.68 years $(S D=5.11)$ at the start of the study. In the RADAR study, identity was assessed from T2 onward. Therefore, the present study used data from five annual waves: T2, T3, T4, T5, T6 (which we will refer to as T1 through T5, respectively). Before the start of the study, adolescents and their parents were recruited through randomly selected secondary schools from central and western parts in the Netherlands. All participants signed an informed consent form. Adolescents filled out paper-and-pencil questionnaires during home visits. The med- ical ethical committee of the University Medical Center Utrecht (Protocol No. 05/159-K) approved the RADAR study.

Missing value analyses indicated that, on average, $90 \%$ of all possible data points were completed by adolescents across five waves. Little's (1988) missing completely at random (MCAR) test revealed a normed chi-square $\left(\chi^{2} / d f\right)$ of 1.22 across study variables. Therefore, missing data were handled in Mplus (Version 8.1; Muthén and Muthén, 1998-2017) using full information maximum likelihood (FIML).

Of the 497 participants who agreed to participate, 466 adolescents $(93.8 \%)$ completed questionnaires at T1. Sample attrition across time was low, with $88.3 \%$ of adolescents who participated at $\mathrm{T} 1$ still participating at $\mathrm{T} 5$. We conducted additional attrition analyses in order to compare whether adolescents who dropped out over the course of the study differed on any of the T1 study variables relative to adolescents who still participated. Results revealed no significant mean-level differences on any of the study variables (i.e., identity processes and depressive symptoms) at T1, $F(4,461)=1.00, p=.828, \eta_{p}^{2}=.00$. Hence, based on the empirical support for the data being MCAR, and additional attrition analyses, we decided to make use of all available data and include all adolescents with and without missing data in our analyses.

Measures.

Identity. Adolescents completed the Utrecht Management of Identity Commitment Scale (U-MICS; Crocetti et al., 2008) to assess their identity. In total, 26 items tapped into three key identity processes in two identity domains (i.e., educational and interpersonal domain). Within each domain, identity commitment was assessed with five items, (e.g., "My education/best friend makes me feel confident about myself"), in-depth exploration was assessed with five items (e.g., "I often think about my education/ best friend"), and reconsideration of commitment was assessed with three items (e.g., "In fact, I'm looking for a different education/best friend"). Adolescents rated these items on a 5-point Likert scale $(1=$ completely untrue, $5=$ completely true $)$. For the purpose of the present study, we computed mean global identity scores by combining the educational and interpersonal identity domains (e.g., Crocetti et al., 2008). Factorial validity and measurement invariance across age groups has been supported for the assessment of global identity with the U-MICS (Crocetti et al., 2015). Reliability across waves in the present sample ranged from .95 to .96 for commitment, from .87 to .88 for in-depth exploration, and from .89 to .93 for reconsideration.

Depressive symptoms. Adolescents completed the Reynolds Adolescent Depression Scale (2nd ed.; RADS-2; Reynolds, 2000) as a measure of depressive symptoms. All 30 items (e.g., "I am sad") were answered on a 4-point Likert scale ( 1 = almost never $)$ to 4 (usually). All items were summed into one depressive symptoms score. Reliability and validity have been supported for the RADS-2 (Osman, Gutierrez, Bagge, Fang, \& Emmerich, 2010). In our sample, reliability across five waves ranged from .94 to .95.

\section{Results}

Means, standard deviations, and correlations between study variables are presented in Table 1 .

Identity and depressive symptoms: Direction of associations. Model fit of the fully constrained model was good, $\chi^{2}(152)=$ 
Table 1

Means, Standard Deviations, and Within-Time Correlations of Identity Dimensions and Depressive Symptoms (Study 1)

\begin{tabular}{|c|c|c|c|c|c|c|c|c|c|}
\hline \multirow[b]{2}{*}{ Dimension } & \multicolumn{5}{|c|}{ Descriptive statistics } & \multicolumn{4}{|c|}{ Within-time correlations at $\mathrm{T} 1$ and $\mathrm{T} 5$} \\
\hline & $\mathrm{T} 1, M(S D)$ & $\mathrm{T} 2, M(S D)$ & $\mathrm{T} 3, M(S D)$ & $\mathrm{T} 4, M(S D)$ & $\mathrm{T} 5, M(S D)$ & $\mathrm{COM}$ & REC & ED & DEP \\
\hline $\mathrm{COM}$ & $3.66(.63)$ & $3.62(.66)$ & $3.60(.66)$ & $3.64(.69)$ & $3.57(.72)$ & & $-.27^{* * * *}$ & $.56^{* * * *}$ & $-.26^{* * * *}$ \\
\hline REC & $1.87(.75)$ & $1.84(.73)$ & $1.89(.76)$ & $1.88(.76)$ & $2.02(.81)$ & $-.41^{* * * * *}$ & & .02 & $.21^{* * *}$ \\
\hline ED & $3.24(.64)$ & $3.25(.64)$ & $3.18(.66)$ & $3.25(.66)$ & $3.21(.65)$ & $.56^{* * * *}$ & -.08 & & -.06 \\
\hline DEP & $34.60(11.43)$ & $25.25(12.05)$ & $35.90(12.33)$ & 35.37 (11.78) & $36.60(12.55)$ & $-.31^{* * * * *}$ & $.29^{* * * * *}$ & -.05 & \\
\hline$N$ & 466 & 451 & 437 & 420 & 425 & & & & \\
\hline
\end{tabular}

Note. Time $1(\mathrm{~T} 1)=$ within-time correlations are displayed above the diagonal; Time $5(\mathrm{~T} 5)=$ within-time correlations are shown below the diagonal; $\mathrm{T} 2=$ Time $2 ; \mathrm{T} 3=$ Time $3 ; \mathrm{T} 4=$ Time $4 ; \mathrm{COM}=$ commitment; $\mathrm{REC}=$ reconsideration; $\mathrm{ED}=$ exploration in-depth; DEP $=$ depressive symptoms. ${ }^{*} p<.05 .^{* *} p<.01 .{ }^{* * * *} p<.001$.

197.41, $p=.008, \mathrm{CFI}=0.99, \mathrm{RMSEA}=0.03$, and SRMR $=$ 0.06. Freeing our parameters of interest (i.e., cross-lagged paths) did not significantly improve model fit, $\Delta \mathrm{S}-\mathrm{B} \chi^{2}(36)=$ $48.40, p=.078$, as compared with a constrained model. We kept the most parsimonious model with all parameters (i.e., stability paths, correlated changes and all possible cross-lagged effects) set to be time invariant. Consistent with the vulnerability model, when adolescents increased in reconsideration of commitment they showed an increase in depressive symptoms one wave later. Depressive symptoms did not predict identity. No other significant cross-lagged effects were found between identity processes and depressive symptoms (Figure 1 displays standardized cross-lagged paths and T1 correlations; correlated changes across T2-T5 are presented in the online supplementary material in Table S1).

In addition, we examined whether cross-lagged effects among the identity processes and between identity processes and depressive symptoms were different for boys and girls. To this end, we specified a model in which all cross-lagged effects were freely estimated for boys and girls separately and compared this model with a model in which all cross-lagged effects were set equal for boys and girls. Results indicated no moder- ation effects: Freeing the cross-paths for boys and girls did not significantly improve the model fit, $\Delta \mathrm{S}-\mathrm{B} \chi^{2}(12)=9.64, p=$ .647 , suggesting no significant differences between boys and girls in the associations between identity processes and depressive symptoms.

\section{Study 2}

Next, we investigated whether we could replicate our findings from Study 1 in a second longitudinal sample of adolescents. In Study 2 we applied a different identity process model developed by Luyckx and colleagues (Luyckx, Goossens, \& Soenens, 2006; Luyckx, Schwartz, Berzonsky, et al., 2008), that is conceptually closely related to the Meeus-Crocetti identity process model, as employed in Study 1 (Crocetti et al., 2008; Meeus et al., 2010).

\section{Method}

Participants and procedure. Participants were 1,022 adolescents $\left(63 \%\right.$ girls, $M_{\text {age }}$ T1 $=15.80$ years, $S D=1.29$, range 12-21 years) who took part in the longitudinal Personality and

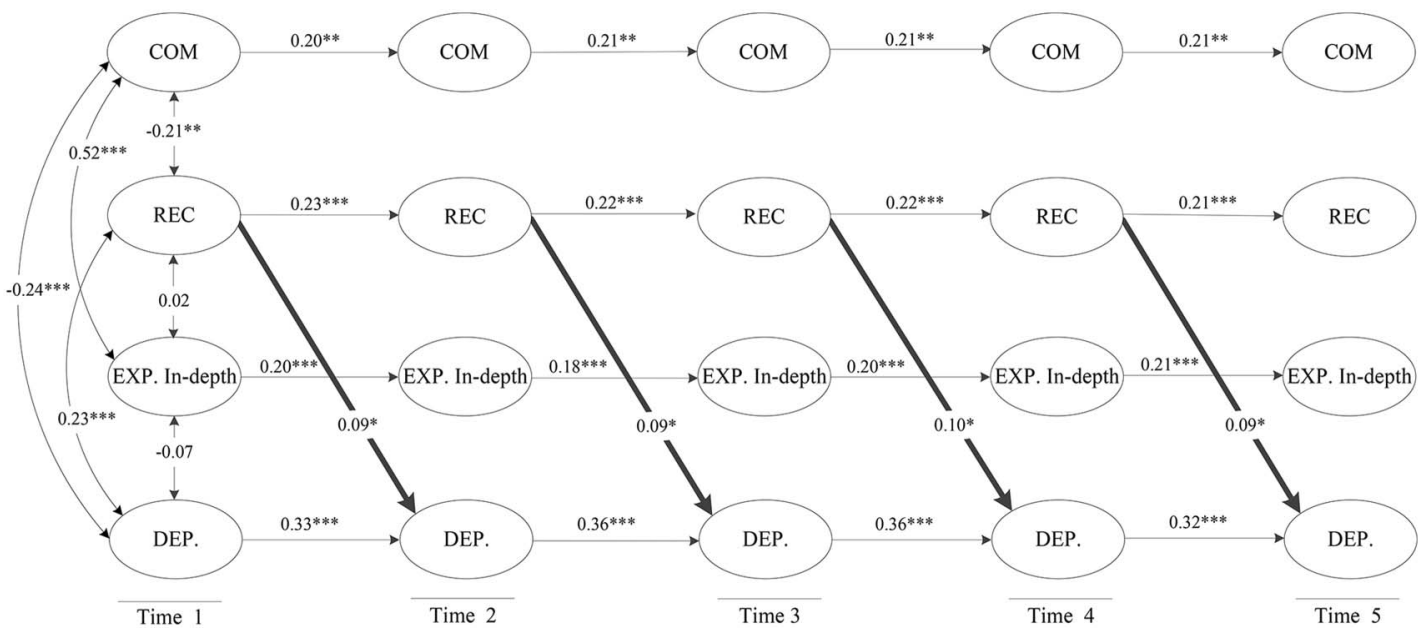

Figure 1. Within-person cross-lagged panel model (Study 1: Research on Adolescent Development and Relationships [RADAR] data) with standardized associations between identity processes and depressive symptoms. $\mathrm{COM}=$ commitment, $\mathrm{REC}=$ reconsideration, EXP. In-depth $=$ exploration in-depth, DEP $=$ depressive symptoms. ${ }^{*} p<.05$. ${ }^{* *} p<.01$. $^{* * *} p<.001$. 
Loneliness/Solitude (PALS) study. Virtually all participants had the Belgian nationality. Most participants indicated that they were living with both parents $(83 \%)$; some lived with their mothers $(7 \%)$ or in another family constellation (10\%). Data collection took place in one secondary school from Flanders, the Dutch-speaking region of Belgium. This secondary school is known to attract students from middle class socioeconomic backgrounds. Active written informed consent was obtained from parents and assent was obtained from all adolescents. We used all four waves available, which we refer to as T1 through T4, respectively. Each year, adolescents completed questionnaires in their classroom during regular school time. All paperand-pencil questionnaires were administrated in Dutch. The study was approved by the Institutional Review Board of the Catholic University of Leuven.

Missing value analyses indicated that $68 \%$ of all possible data points were completed by adolescents across waves. Little's (1988) MCAR test revealed a normed chi-square $\left(\chi^{2} / d f\right)$ of 1.07 , indicating that it is unlikely that our findings were biased as a result of missing values. Hence, missing values could be reliably dealt with using FIML.

Of the 1,022 participants who agreed to participate, 1,016 adolescents $(99.4 \%)$ completed questionnaires at T1. Sample attrition across time was relatively larger compared with Study 1 . Specifically, $43.2 \%$ of the adolescents who participated at T1 still participated at $\mathrm{T} 4$. We conducted additional attrition analyses by comparing the group of adolescents who dropped out across study waves with the adolescents who still participated. Results revealed no significant mean-level differences on any of the study variables (i.e., identity processes and depressive symptoms) at T1, $F(3$, $1012)=1.86, p=.135, \eta_{p}^{2}=.01$. Given the empirical support for the data MCAR, along with the nonsignificant attrition analyses, we decided to make use of all available data, and include adolescents with and without missing data in all subsequent analyses.

\section{Measures.}

Identity. To assess their identity, adolescents completed the 25-item Dimensions of Identity Development Scale (DIDS; Luyckx, Schwartz, Berzonsky, et al., 2008). For the purpose of conceptual comparison between Study 1 and Study 2, we included the three identity processes that are conceptually closely related to the processes of the Meeus-Crocetti model that was applied in Study 1: identification with commitment (e.g., "I sense that the direction I want to take in my life will really suit me"), in-depth exploration ("I regularly talk with other people about the plans for the future I have made for myself"), and ruminative exploration ("It is hard for me to stop thinking about the direction I want to follow in my life"), answered on a 5-point Likert scale $(1=$ strongly disagree, $5=$ strongly agree $)$. For each identity dimension, we computed the mean score There is ample empirical support for construct validity and reliability of the DIDS in different samples (e.g., Luyckx, Schwartz, Berzonsky, et al., 2008). Across waves, reliability was good with Cronbach's alpha ranging from .87 to .90 for identification with commitment, from .78 to .82 for in-depth exploration and from .83 to .88 for ruminative exploration.

Depressive symptoms. Adolescents completed a brief Dutch version (Hooge, Decaluwé, \& Goossens, 2000) of the Center for Epidemiologic Studies Depression Scale (CES-D; Radloff, 1977; Roberts \& Sobhan, 1992) to assess depressive symptoms. All 12 items (e.g., "During the last week, I felt depressed") were answered on a 4 -point Likert scale $(1=$ seldom, $4=$ most of the time or always), and summed into one depressive symptoms score. Across waves, Cronbach's alpha ranged from .83 to .85 .

\section{Results}

Means, standard deviations, and correlations between study variables are presented in Table 2 .

Identity and depressive symptoms: Direction of associations. Model fit of the fully constrained model was good, $\chi^{2}(82)=$ $137.60, p=.000, \mathrm{CFI}=0.98$, RMSEA $=0.03$, and $\mathrm{SRMR}=$ 0.04. Freeing all parameters of interest (i.e., the cross-lagged paths) did not significantly improve model fit, $\Delta \mathrm{S}-\mathrm{B} \chi^{2}(24)=$ $30.91, p=.156$, as compared with the fully constrained model. Therefore, we kept the most parsimonious model with parameters set to be time-invariant.

Similar to Study 1 and consistent with the vulnerability model, adolescents' increasing ruminative exploration predicted a withinperson increase in depressive symptoms one wave later, but not vice versa. No other significant cross-lagged effects between identity processes and depressive symptoms were found (Figure 2 displays standardized cross-lagged paths and concurrent associations at $\mathrm{T} 1$; correlated changes across $\mathrm{T} 2-\mathrm{T} 4$ are presented in the online supplementary material in Table S2).

Similar to Study 1, we tested possible differences in the crosslagged associations between boys and girls. Accordingly, we compared a model in which all cross-lagged effects were freely esti-

Table 2

Means, Standard Deviations, and Within-Time Correlations of Identity Dimensions and Depressive Symptoms (Study 2)

\begin{tabular}{|c|c|c|c|c|c|c|c|c|}
\hline \multirow[b]{2}{*}{ Dimension } & \multicolumn{4}{|c|}{ Descriptive statistics } & \multicolumn{4}{|c|}{ Within-time correlations at $\mathrm{T} 1$ and $\mathrm{T} 4$} \\
\hline & $\mathrm{T} 1, M(S D)$ & $\mathrm{T} 2, M(S D)$ & $\mathrm{T} 3, M(S D)$ & $\mathrm{T} 4, M(S D)$ & IC & $\mathrm{RE}$ & ED & DEP \\
\hline IC & $3.44(.77)$ & $3.47(.75)$ & $3.57(.78)$ & $3.64(.72)$ & & $-.34^{* * * *}$ & $.45^{* * * *}$ & $-.25^{* * * *}$ \\
\hline $\mathrm{RE}$ & $2.80(.84)$ & $2.83(.86)$ & $2.73(.90)$ & $2.71(.88)$ & $-.48^{* * * *}$ & & $.14^{* * * *}$ & $.28^{\text {***** }}$ \\
\hline ED & $3.25(.73)$ & $3.38(.72)$ & $3.47(.71)$ & $3.58(.67)$ & $.45^{* * * *}$ & .01 & & $-.09^{* * *}$ \\
\hline DEP & $10.26(5.88)$ & $9.94(5.93)$ & $9.64(5.85)$ & $8.88(5.58)$ & $-.38^{* * * *}$ & $.33^{* * * *}$ & -.05 & \\
\hline$N$ & 1,022 & 727 & 605 & 442 & & & & \\
\hline
\end{tabular}

Note. $\mathrm{T} 1=$ within-time correlations are displayed above the diagonal; $\mathrm{T} 4=$ within-time correlations are shown below the diagonal; $\mathrm{T} 2=\mathrm{Time} 2 ; \mathrm{T} 3=$ Time 3; IC = identification with commitment; $\mathrm{RE}=$ ruminative exploration; $\mathrm{ED}=$ exploration in-depth; $\mathrm{DEP}=$ depressive symptoms .

${ }^{*} p<.05 .{ }^{* * *} p<.01 .{ }^{* * * *} p<.001$ 


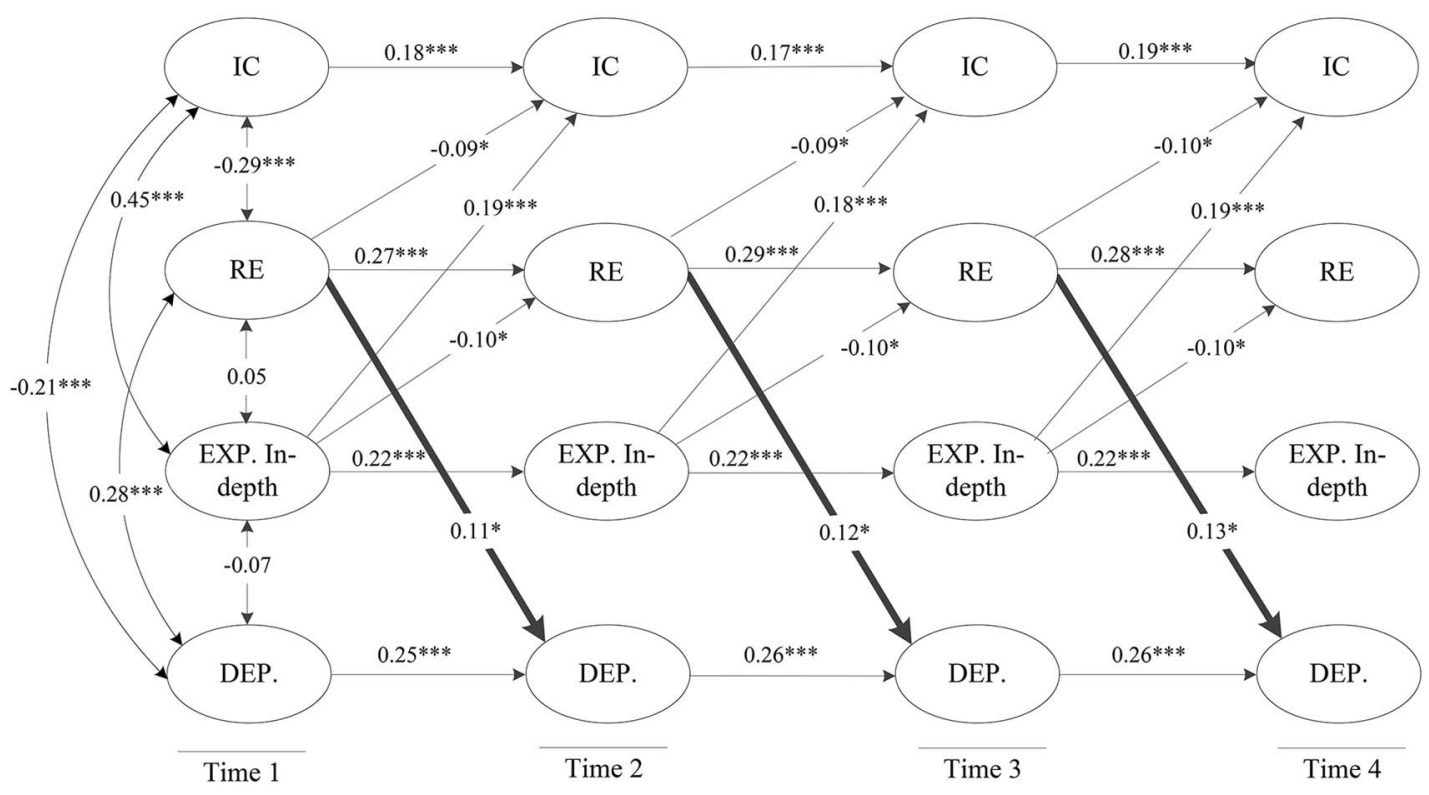

Figure 2. Within-person cross-lagged panel model (Study 2; Personality and Loneliness/Solitude [PALS] data) with standardized associations between identity processes and depressive symptoms. IC $=$ identification with commitment, $\mathrm{RE}=$ ruminative exploration, EXP. In-depth $=$ exploration in-depth, DEP $=$ depressive symptoms. ${ }^{*} p<.05 .{ }^{* *} p<.01 .{ }^{* * * *} p<.001$.

mated for boys and girls with a model in which all cross-lagged effects were set equal for boys and girls. Again, results indicated no moderation effects: Freeing the cross-paths for boys and girls did not significantly improve the model fit, $\Delta \mathrm{S}-\mathrm{B} \chi^{2}(12)=17.18$, $p=.143$, suggesting no significant differences between boys and girls in the associations between identity processes and depressive symptoms.

Although not directly relevant for our study aim, increasing ruminative exploration predicted less identification with commitment 1 wave later. In addition, increasing in-depth exploration predicted more identification with commitment and less ruminative exploration one wave later.

\section{Discussion}

The present study tested two theoretical perspectives on the within-person linkages between identity and depressive symptoms in two longitudinal adolescent samples. Our findings supported the vulnerability model and contradicted the scar model. That is, when adolescents became increasingly uncertain and increasingly hesitant about their identity, they reported more depressive symptoms 1 year later, but not vice versa.

Inspired by a recent call for replication in developmental studies (Duncan, Engel, Claessens, \& Dowsett, 2014), we found this unidirectional effect in two samples from two countries (i.e., the Netherlands and Belgium). Further, we applied two conceptually comparable, yet different assessments of process-oriented identity models (U-MICS and DIDS questionnaires in Studies 1 and 2, respectively; Crocetti et al., 2008; Luyckx, Schwartz, Berzonsky, et al., 2008), and different questionnaires to assess depressive symptoms (RADS and CES-D in Studies 1 and 2, respectively; Radloff, 1977; Reynolds, 2000). Despite these different assess- ments of identity and depressive symptoms, findings in both studies were strikingly similar.

\section{Identity Processes and Depressive Symptoms}

Both studies highlighted a particularly important role of reconsideration of commitment and ruminative exploration. Recently, these processes have been referred to as the maladaptive or dark side of identity formation, and have been marked as clear indicators of when adolescents' identity formation goes awry (Crocetti, Beyers, \& Çok, 2016). The present findings add to this literature by showing that when adolescents increasingly come to doubt their identity and get stuck in the identity exploration process, they are at risk for developing depressive symptoms. Our results are consistent with previous literature showing that adolescents' daily fluctuations in identity reconsideration predicted later depressive symptoms, but not vice versa (Schwartz et al., 2011). Withinperson changes in commitment or in-depth exploration did not predict depressive symptoms over time, nor did we find evidence for bidirectional associations between identity processes and depressive symptoms (Schwartz et al., 2012). Possibly, a withinperson increase in identity reconsideration and ruminative exploration most strongly signals identity confusion to adolescents whereas fluctuations in their level of commitment and in-depth exploration are experienced as less problematic and stressful to them.

\section{Vulnerability for Boys and Girls Across Adolescence}

Our findings in favor of the vulnerability model were found for both boys and girls. Thus, when both boys and girls experienced more identity uncertainty than they usually do, they 
were at risk of developing more depressive symptoms over time. Hence, despite consistent evidence that girls report higher mean levels of depressive symptoms (Meeus, 2016), and higher levels of identity uncertainty (e.g., Luyckx, Schwartz, Berzonsky, et al., 2008), their level of depressive symptoms are equally affected by increasing identity uncertainty. In other words, regardless of mean-level differences between boys and girls, the within-person mechanism (i.e., identity uncertainty predicting increasing depressive symptoms) seems to be comparable across sex. Moreover, we replicated this effect from identity uncertainty to depressive symptoms across the entire period of adolescence. From a broader developmental perspective this consistency in the association across sex and time further supports the notion that the formation of a stable sense of identity is a central task for most adolescents, that is intrinsically linked to their mental health (Erikson, 1968; Klimstra \& Denissen, 2017).Yet, an important question for future work is to investigate whether the time invariance of the association between identity processes and depressive symptoms holds across adolescence into young adulthood. For example, previous cross-sectional work has found that identity exploration processes become more strongly related to depressive symptoms in young adulthood compared with adolescence (Luyckx et al., 2013).

Although our findings support the vulnerability model, future studies need to investigate possible underlying mechanisms. For example, adolescents' continuing identity uncertainty and a lack of pursuing personal goals (i.e., identity commitments) have been related to less personal meaning in life (Negru-Subtirica, Pop, Luyckx, Dezutter, \& Steger, 2016). In turn, lower meaning in life may feed into the development of depressive symptoms over time. This, and potentially other mediational mechanisms, need to be tested in longitudinal research.

\section{Within-Person Longitudinal Associations: Theoretical Implications}

Our findings highlight the usefulness of applying the vulnerability and scar models to the field of identity research. However, these theoretical models originate from the personality literature, which has been generally focused on studying between-person differences in personality traits. Applied to the identity-depression linkages, the original vulnerability model emphasizes that betweenperson differences in identity uncertainty is a risk factor for developing depressive symptoms. That is, adolescents with levels of identity uncertainty higher than their peers are likely to be the ones to experience higher levels of depressive symptoms. However, our within-person results highlight that these models should be applicable to explain within-person processes, that is, how within-person change in identity (regardless of the level on the respective identity dimension) is a risk factor of within-person change in depressive symptoms. In addition to the vulnerability and scar theoretical models that mainly hypothesize about between-person associations, the majority of the empirical studies currently available tend to focus on associations at the betweenperson level as well (Curran \& Bauer, 2011; Klimstra \& Denissen, 2017). Hence, future studies are needed to further test and refine theoretical models on the linkages between identity and psychopathology at the within-person level.
Inevitably, the current study has some limitations. First, adolescents reported both on their identity processes and depressive symptoms, which might have inflated some of our findings as a result of shared method variance. However, identity formation processes are subjective, and therefore most suitable to assess with self-reports. While depressive symptoms have been found to be best judged with self-reports as well (Vierhaus \& Lohaus, 2008), future studies should investigate to what extent our findings hold when using multi-informant (e.g., parent-reported) assessments of adolescents' depressive symptoms. Second, both studies mainly included Dutch (Study 1) or Belgian (Study 2) Caucasian adolescents. Hence, the ethnic diversity of both samples was rather low. While this is an obvious limitation of the present study, future work should investigate whether our findings generalize to more diverse samples. For example, it has been suggested that the development of a strong identity is especially important for minority groups (Phinney, 1990). Therefore, failing to establish strong identity commitments and experiencing ongoing identity uncertainty may be more strongly related to subsequent depressive symptoms, especially for ethnic minorities. One recent study on ethnic identity (referring to the extent to which individuals identify with and derive meaning from their ethnicity) did not find consistent support for a stronger association between ethnic identity and depressive symptoms for ethnic minorities compared with majority groups (i.e., Whites; Syed \& Juang, 2014). However, whether this finding also generalizes to personal identity, like their educational and friendship identity, rather than ethnic identity specifically, remains an important direction for future research. Third, while our within-person cross-lagged panel model allowed us to test the direction of associations between identity and depressive symptoms, these results represent the average within-person effects across the entire sample. Future studies should further investigate possible heterogeneity in these within-person processes (Keijsers, 2016). Fourth, identity formation processes do not develop in a social void, but in close interaction with significant others (e.g., Crocetti, Branje, Rubini, Koot, \& Meeus, 2017). Therefore, future research should inform us on how quality of relationships with parents and peers may mitigate or increase the links between identity and depressive symptoms.

Despite these limitations, the present study is the first to combine two important process-oriented identity models in a single study assessing the prospective within-person associations linking identity processes to depressive symptoms. Collectively, in line with the vulnerability model, the findings support the view that a within-person increase in adolescents' identity uncertainty is a risk factor for the development of depressive symptoms. Hence, our findings highlight potentially important consequences when young people experience identity confusion.

\section{References}

Becht, A. I., Bos, M. G. N., Nelemans, S. A., Peters, S., Vollebergh, W. A. M., Branje, S. J. T., . . . Crone, E. A. (2018). Goal-directed correlates and neurobiological underpinnings of adolescent identity: a multimethod multisample longitudinal approach. Child Development, 89, 823-836. http://dx.doi.org/10.1111/cdev.13048 
Branje, S., \& Meeus, W. H. J. (2018). Research on Adolescent Development and Relationships (RADAR young cohort). Retrieved from Data Archiving and Networked Service; Netherlands Institute for permanent access to digital research resources: https://easy.dans.knaw.nl/ui/ datasets/id/easy-dataset:113721

Burrow, A. L., \& Hill, P. L. (2011). Purpose as a form of identity capital for positive youth adjustment. Developmental Psychology, 47, 11961206. http://dx.doi.org/10.1037/a0023818

Byrne, B. M. (2013). Structural equation modeling with Mplus: Basic concepts, applications, and programming. New York, NY: Routledge.

Crocetti, E. (2017). Identity formation in adolescence: The dynamic of forming and consolidating identity commitments. Child Development Perspectives, 11, 145-150. http://dx.doi.org/10.1111/cdep.12226

Crocetti, E., Beyers, W., \& Çok, F. (2016). Shedding light on the dark side of identity: Introduction to the special issue. Journal of Adolescence, 47, 104-108. http://dx.doi.org/10.1016/j.adolescence.2016.01.002

Crocetti, E., Branje, S., Rubini, M., Koot, H. M., \& Meeus, W. (2017). Identity processes and parent-child and sibling relationships in adolescence: A five-wave multi-informant longitudinal study. Child Development, 88, 210-228. http://dx.doi.org/10.1111/cdev.12547

Crocetti, E., Cieciuch, J., Gao, C. H., Klimstra, T., Lin, C. L., Matos, P. M., . . Meeus, W. (2015). National and gender measurement invariance of the Utrecht-Management of Identity Commitments Scale (U-MICS). Assessment, 22, 753-768. http://dx.doi.org/10.1177/1073191115584969

Crocetti, E., Rubini, M., \& Meeus, W. (2008). Capturing the dynamics of identity formation in various ethnic groups: Development and validation of a three-dimensional model. Journal of Adolescence, 31, 207-222. http://dx.doi.org/10.1016/j.adolescence.2007.09.002

Curran, P. J., \& Bauer, D. J. (2011). The disaggregation of within-person and between-person effects in longitudinal models of change. Annual Review of Psychology, 62, 583-619. http://dx.doi.org/10.1146/annurev .psych.093008.100356

Duncan, G. J., Engel, M., Claessens, A., \& Dowsett, C. J. (2014). Replication and robustness in developmental research. Developmental Psychology, 50, 2417-2425. http://dx.doi.org/10.1037/a0037996

Durbin, C. E., \& Hicks, B. M. (2014). Personality and psychopathology: A stagnant field in need of development. European Journal of Personality, 28, 362-386. http://dx.doi.org/10.1002/per.1962

Erikson, E. (1968). Youth and crisis. New York, NY: Norton.

Hamaker, E. L., Kuiper, R. M., \& Grasman, R. P. (2015). A critique of the cross-lagged panel model. Psychological Methods, 20, 102-116. http:// dx.doi.org/10.1037/a0038889

Hankin, B. L., Young, J. F., Abela, J. R., Smolen, A., Jenness, J. L., Gulley, L. D., . . Oppenheimer, C. W. (2015). Depression from childhood into late adolescence: Influence of gender, development, genetic susceptibility, and peer stress. Journal of Abnormal Psychology, 124, 803-816. http://dx.doi.org/10.1037/abn0000089

Hooge, N., Decaluwé, L., \& Goossens, L. (2000). Identiteit en psychisch welbevinden. [Identity and psychological well-being] In J. H. H. De Witte \& L. Walgrave (Eds.), Jongeren in Vlaanderen: Gemeten en geteld. 12- tot 18-jarigen over hun leefwereld en toekomst (pp. 35-57). Leuven, Belgium: Universitaire Pers Leuven.

Keijsers, L. (2016). Parental monitoring and adolescent problem behaviors. International Journal of Behavioral Development, 40, 271-281. http:// dx.doi.org/10.1177/0165025415592515

Kessler, R. C., Berglund, P., Demler, O., Jin, R., Merikangas, K. R., \& Walters, E. E. (2005). Lifetime prevalence and age-of-onset distributions of DSM-IV disorders in the National Comorbidity Survey Replication. Archives of General Psychiatry, 62, 593-602. http://dx.doi.org/10.1001/ archpsyc.62.6.593

Klimstra, T. A., \& Denissen, J. J. A. (2017). A theoretical framework for the associations between identity and psychopathology. Developmental Psychology, 53, 2052-2065. http://dx.doi.org/10.1037/dev0000356
Klimstra, T. A., Hale, W. W., III, Raaijmakers, Q. A., Branje, S. J., \& Meeus, W. H. (2010). Identity formation in adolescence: Change or stability? Journal of Youth and Adolescence, 39, 150-162. http://dx.doi org/10.1007/s10964-009-9401-4

Little, R. J. (1988). A test of missing completely at random for multivariate data with missing values. Journal of the American Statistical Association, 83, 1198-1202. http://dx.doi.org/10.1080/01621459.1988.10478722

Luyckx, K., Duriez, B., Klimstra, T. A., \& De Witte, H. (2010). Identity statuses in young adult employees: Prospective relations with work engagement and burnout. Journal of Vocational Behavior, 77, 339-349. http://dx.doi.org/10.1016/j.jvb.2010.06.002

Luyckx, K., Goossens, L., \& Soenens, B. (2006). A developmental contextual perspective on identity construction in emerging adulthood: Change dynamics in commitment formation and commitment evaluation. Developmental Psychology, 42, 366-380. http://dx.doi.org/10.1037/0012-1649.42.2.366

Luyckx, K., Klimstra, T. A., Duriez, B., Van Petegem, S., \& Beyers, W. (2013). Personal identity processes from adolescence through the late 20s: Age trends, functionality, and depressive symptoms. Social Development, 22, 701-721. http://dx.doi.org/10.1111/sode.12027

Luyckx, K., Schwartz, S. J., Berzonsky, M. D., Soenens, B., Vansteenkiste, M., Smits, I., \& Goossens, L. (2008). Capturing ruminative exploration: Extending the four-dimensional model of identity formation in late adolescence. Journal of Research in Personality, 42, 58-82. http://dx .doi.org/10.1016/j.jrp.2007.04.004

Luyckx, K., Schwartz, S. J., Goossens, L., Soenens, B., \& Beyers, W. (2008). Developmental typologies of identity formation and adjustment in female emerging adults: A latent class growth analysis approach. Journal of Research on Adolescence, 18, 595-619. http://dx.doi.org/10 .1111/j.1532-7795.2008.00573.x

Marcia, J. E. (1966). Development and validation of ego-identity status. Journal of Personality and Social Psychology, 3, 551-558. http://dx.doi .org/10.1037/h0023281

Marcia, J. E. (1980). Identity in adolescence. In J. Adelson (Ed.), Handbook of adolescent psychology (pp. 159-187). New York, NY: Wiley.

Meeus, W. (2011). The study of adolescent identity formation 2000-2010: A review of longitudinal research. Journal of Research on Adolescence, 21, 75-94. http://dx.doi.org/10.1111/j.1532-7795.2010.00716.x

Meeus, W., van de Schoot, R., Keijsers, L., \& Branje, S. (2012). Identity statuses as developmental trajectories: A five-wave longitudinal study in early-to-middle and middle-to-late adolescents. Journal of Youth and Adolescence, 41, 1008-1021. http://dx.doi.org/10.1007/s10964-011-9730-y

Meeus, W., van de Schoot, R., Keijsers, L., Schwartz, S. J., \& Branje, S. (2010). On the progression and stability of adolescent identity formation: A five-wave longitudinal study in early-to-middle and middle-to-late adolescence. Child Development, 81, 1565-1581. http://dx.doi.org/10.1111/j .1467-8624.2010.01492.x

Meeus, W. (2016). Adolescent psychosocial development: A review of longitudinal models and research. Developmental Psychology, 52, 1969-1993. http://dx.doi.org/10.1037/dev0000243

Molenaar, P. C., \& Campbell, C. G. (2009). The new person-specific paradigm in psychology. Current Directions in Psychological Science, 18, 112-117. http://dx.doi.org/10.1111/j.1467-8721.2009.01619.x

Muthén, L. (2010). Mplus Users Guide [Computer Software and Manual]. Los Angeles, CA: Author.

Muthén, L. K., \& Muthén, B. O. (1998-2017). Mplus user's guide (8th ed.). Los Angeles, CA: Author.

Negru-Subtirica, O., Pop, E. I., Luyckx, K., Dezutter, J., \& Steger, M. F. (2016). The meaningful identity: A longitudinal look at the interplay between identity and meaning in life in adolescence. Developmental Psychology, 52, 1926-1936. http://dx.doi.org/10.1037/dev0000176

Osman, A., Gutierrez, P. M., Bagge, C. L., Fang, Q., \& Emmerich, A. (2010). Reynolds Adolescent Depression Scale-2nd ed.: A reliable and useful instrument. Journal of Clinical Psychology, 66, 1324-1345. http://dx.doi.org/10.1002/jclp.20727 
Petersen, A. C., Compas, B. E., Brooks-Gunn, J., Stemmler, M., Ey, S., \& Grant, K. E. (1993). Depression in adolescence. American Psychologist, 48, 155-168. http://dx.doi.org/10.1037/0003-066X.48.2.155

Phinney, J. S. (1990). Ethnic identity in adolescents and adults: review of research. Psychological Bulletin, 108, 499-514. http://dx.doi.org/10 $.1037 / / 0033-2909.108 .3 .499$

Radloff, L. S. (1977). The CES-D Scale. Applied Psychological Measurement, 1, 385-401. http://dx.doi.org/10.1177/014662167700100306

Reynolds, W. (2000). Reynolds Adolescent Depression Scale-2nd edition (RADS-2). Odessa, FL: Psychological Assessment Resources.

Roberts, R. E., \& Sobhan, M. (1992). Symptoms of depression in adolescence: A comparison of Anglo, African, and Hispanic Americans. Journal of Youth and Adolescence, 21, 639-651. http://dx.doi.org/10.1007/ BF01538736

Schwartz, S. J., Klimstra, T. A., Luyckx, K., Hale, W. W., III, Frijns, T., Oosterwegel, A., . . Meeus, W. H. (2011). Daily dynamics of personal identity and self-concept clarity. European Journal of Personality, 25, 373-385. http://dx.doi.org/10.1002/per.798
Schwartz, S. J., Klimstra, T. A., Luyckx, K., Hale, W. W., III, \& Meeus, W. H. (2012). Characterizing the self-system over time in adolescence: Internal structure and associations with internalizing symptoms. Journal of Youth and Adolescence, 41, 1208-1225. http://dx.doi.org/10.1007/ s10964-012-9751-1

Syed, M., \& Juang, L. P. (2014). Ethnic identity, identity coherence, and psychological functioning: Testing basic assumptions of the developmental model. Cultural Diversity and Ethnic Minority Psychology, 20, 176-190. http://dx.doi.org/10.1037/a0035330

Vierhaus, M., \& Lohaus, A. (2008). Children and parents as informants of emotional and behavioural problems predicting female and male adolescent risk behaviour: A longitudinal cross-informant study. Journal of Youth and Adolescence, 37, 211-224. http://dx.doi.org/10.1007/s10964007-9193-3

Received April 4, 2018

Revision received February 14, 2019

Accepted March 20, 2019

\section{Members of Underrepresented Groups: Reviewers for Journal Manuscripts Wanted}

If you are interested in reviewing manuscripts for APA journals, the APA Publications and Communications Board would like to invite your participation. Manuscript reviewers are vital to the publications process. As a reviewer, you would gain valuable experience in publishing. The P\&C Board is particularly interested in encouraging members of underrepresented groups to participate more in this process.

If you are interested in reviewing manuscripts, please write APA Journals at Reviewers@apa.org. Please note the following important points:

- To be selected as a reviewer, you must have published articles in peer-reviewed journals. The experience of publishing provides a reviewer with the basis for preparing a thorough, objective review.

- To be selected, it is critical to be a regular reader of the five to six empirical journals that are most central to the area or journal for which you would like to review. Current knowledge of recently published research provides a reviewer with the knowledge base to evaluate a new submission within the context of existing research.

- To select the appropriate reviewers for each manuscript, the editor needs detailed information. Please include with your letter your vita. In the letter, please identify which APA journal(s) you are interested in, and describe your area of expertise. Be as specific as possible. For example, "social psychology" is not sufficient-you would need to specify "social cognition" or "attitude change" as well.

- Reviewing a manuscript takes time (1-4 hours per manuscript reviewed). If you are selected to review a manuscript, be prepared to invest the necessary time to evaluate the manuscript thoroughly.

APA now has an online video course that provides guidance in reviewing manuscripts. To learn more about the course and to access the video, visit http://www.apa.org/pubs/journals/resources/ review-manuscript-ce-video.aspx. 